\title{
Discussion on the Teaching Method of Probability Theory and Mathematical Statistics
}

\author{
Feng Wang \\ School of Mathematics and Statistics Sciences \\ Xi'an Jiaotong University \\ Xi'an, China
}

\author{
Xiaoping $\mathrm{Xu}$ \\ School of sciences \\ Xi'an University of Technology \\ Xi’an, China
}

\begin{abstract}
In order to improve teaching quality and boost teaching reform for the course of probability and mathematical statistics, some practical research on the curricular contents, teaching method etc are discussed in this paper. In view of the particularity of the study object in the course of probability and mathematical statistics, on the basis of teaching practice of probability and mathematical statistics, combined with my teaching experience, in order to stimulate students' interest in learning and improve students' ability to solve some practical problems, this paper puts forward some suggestions for the teaching of probability and mathematical statistics from the aspects of clearing objective and selecting textbook, adding background knowledge and case, highlighting the practicality and era, introducing interactive heuristic teaching so as to remarkably improve the teaching quality of the course in teaching process and enhance the ability of the students' solving practical problem.
\end{abstract}

Keywords-probability and mathematical statistics; classroom teaching; teaching method; teaching reform

\section{INTRODUCTION}

In the nature and the daily life of human beings, random phenomena are very common. Probability theory and mathematical statistics is mathematical discipline which studies the law of data in random phenomena, and is also one of the important public basic courses for students in colleges and university $[1,2]$. This course is a necessary foundation for subsequent course and in various fields of theoretical research and practical work. Moreover, the course is important for cultivating students' comprehensive ability and improving students' mathematical potential. At present, the theory of probability theory and mathematical statistics is applied to many fields of natural science, such as the field of social science, optimal decision, economic growth, etc. Because of the close relationship between the course and many scientific problems, it is the foundation of many new developing frontier disciplines, so it is very important to learn it for students in the colleges and university [3, 4].

Currently, probability theory and mathematical statistics is an important compulsory course for students majoring in science, engineering, economics and management in colleges and university $[5,6]$. However, due to the special studied object of probability theory and mathematical statistics [7, 8], so there is its unique concept and method compared with other mathematical course in leaning method. In leaning process, students often fall into a dilemma. Many students are unable to digest knowledge in time, even resulting in emotional weariness. Consequently, it is important to improve the teaching effect of probability theory and mathematical statistics. To this end, this paper describes some personal suggestions based on authors' actual teaching experience.

The rest of the paper is organized as follows. In Section II, we explain the clearing objectives and selection of textbook. In Section III, adding background contents of the course are described. Section IV introduces case teaching method. Highlighting practical teaching is explained in Section V. In Section VI, highlighting the era of teaching is described. Section VII introduces the method of interactive heuristic teaching. Finally, in Section VIII, we conclude with a brief summary of our method for probability theory and mathematical statistics.

\section{Clearing Objectives and Selection of TeXtbook}

The phenomenon of nature and human society can be divided into two categories: deterministic phenomenon and nondeterministic phenomenon (i.e., stochastic phenomenon). Probability theory and mathematical statistics is a mathematical discipline to research inherent rule of stochastic phenomenon, its studied object is to determine the role of training students' ability to apply mathematics and random thinking. It is a key to understand the random world. In information age, every citizen should have the ingredients of knowledge structure for understand randomness; it is also a part of personal humanistic quality. Consequently, learning probability theory and mathematical statistics becomes more and more important in the information society.

In summary, in the teaching process for probability theory and mathematical statistics, it is an important issue to clear objectives and selection of textbook.

At first, clearing teaching objectives of probability theory and mathematical statistics are determined to enable students to grasp and deal with stochastic phenomenon using basic theory and method, and practical problems are solved with mathematical theory, moreover, a foundation is established for related disciplines work.

Then, a textbook is selected that it adapt to students, and it has the following characteristics: Firstly, the textbook should 
pay attention to the penetration of statistical thinking and the practical application to prevent the disadvantages of traditional textbook, such as heavy base light application, heavy theory light calculation method. Moreover, the selected examples and exercises are directly from the production and life practice, which can not only deepen understanding basic concepts and method, but also improve the students' interest in learning. Secondly, each section has exercises, each chapter has exercises, and exercises should be comprehensive to meet the needs of different students. Thirdly, some statistical software should be introduced in the textbook, which can cultivate students’ practice ability.

\section{ADDING BACKGROUD KNOWLEDGE}

The teaching of probability theory and mathematical statistics is different from that of advanced mathematics. The latter pays more attention to cultivate mathematical foundation and computing ability while the former not only train the students' basic mathematical knowledge, but also make them understand background knowledge.

In the first class, the teacher should introduce the background of probability theory. For example, probability theory dates back to Italian gambling house in the mid seventeenth century. In 1654, the gambler Lei Mei put forward a reasonable allocation of sweepstakes problems toward the mathematician Pascal. Pascal accepted these problems, but he did not immediately answer, then, he put these questions to mathematician Fermat. Since then, they carefully studied on mathematical problems in gambling. Later, Netherlands mathematician Huygens learned the communication research of Pascal and Fermat, he studied on more complex gambling problems based on the method of permutation and combination, moreover, he wrote a book "the calculation in the gambling" to explore the principle of probability problem in 1657. Finally, the Swiss mathematician Bernoulli conducted important research on probability theory, and made it become a branch of mathematics.

Teacher should combine the specific application model when all kinds of distribution are taught. For example, the teaching of geometric model can be combined with the drunken model; when the Poisson distribution is taught, its application should be pointed, such as it can be used to describe the number of customers arriving at the supermarket in unit time, the number of aircraft arriving at the airport within a unit time, etc. the teaching method can often play a very good effect, and it can reflect the quality of education to a certain extent.

In brief, through the introduction of the background knowledge, students have a preliminary understanding of probability theory and mathematical statistics, and it can enhance the students' learning interest in the colleges and university.

\section{CASE Teaching Method}

Case teaching method is a case-based teaching method. Namely, the basic idea of the teaching method is as follows. After students are guided to practical problems, the basic method of solving problem is put forward through the analysis and mutual discussion. The traditional teaching only tells the students what to do, its content may not be practical in practice, and it is very boring, which may hurt the enthusiasm of the students and the learning effect to some extent.

For example, the idea of hypothesis testing is from small game "tea lady" between the statistical scholars of British Cambridge in 1920s. In the process of tea, a lady said: when tea and milk with different order were added, the taste of tea would be different. In order to prove the lady's statement, the scholar Fisher designed an experiment. In the experiment, the lady drunk a series of modulated tea (the order of tea and milk are different, but Fisher knew their order). Under the premise of Fisher allows for some mistakes, the problem of the hypothesis test was judged. That is to say, the hypothesis testing process is equivalent to the apagoge with probability principle (small probability principle). The null hypothesis and alternative hypothesis are put forward for the hypothesis testing problem initially, then a comprehensive statistic ( testing statistic) is found when the null hypothesis hold, next the statistical value is obtained by sample information, if the statistical value falls into the negative domain, the null hypothesis is rejected, otherwise, the null hypothesis is accepted.

In the process of teaching, through explaining the case, it can not only enable students to master the source of the theory, but also improve students' interest and curiosity, so as to enable students to better grasp the theoretical knowledge and thinking method. In the case teaching, teachers do not need directly telling the solving scheme of the case, but students should think and create, so as to boring learning become lively and interesting. Because the application of probability theory and mathematical statistics is strong, teachers should pay attention to collect the case related to the course, the theory teaching and the actual case is better combined, so as to the class become lively and interesting. Accordingly, the good teaching effect is gotten from the case teaching for probability theory and mathematical statistics.

\section{Highlighting the Practice of Teaching}

The famous mathematical educator Mr. Shijian Yang pointed out [9]: At present, the most fundamental and most effect method of solving the sharp contradiction between the status of our mathematical education and the requirements of the modern society is to strengthen the mathematical education. But higher mathematical education of mathematics department is often classified according to the subject in accordance with the logical deduction system, the application of these systems in social practice and training is rarely provided. Because of the lack of experienced practice exercise, the advantages of the practice have not tasted, thus the active practice is always lack, so the mathematical community should vigorously promote the role of mathematics, and students should know it in school education. Learning mathematics is not only for the entrance, students should know mathematical is useful in practice, so that they can carefully think when they meet a problem. Whether a problem is solved using mathematics, that is, students' application consciousness should be cultivated; they should have application consciousness even without the 
application of skills. Obviously, cultivating students’ applying mathematical skills or consciousness should be borne by mathematics teachers. At present, the graduates only master the theory and method of pure mathematics, but the application ability of mathematical knowledge is weak.

Probability theory and mathematical statistics is developed to solve practical problems in practice, it have rich actual background, it allows students to face practical problems, and the way of solving problem are found from the perspective of mathematics knowledge and method, consequently, probability theory and mathematical statistics plays a special role in cultivating students' application ability.

Firstly, application proportion should strengthen in the course of probability theory and mathematical statistics. Under the premise of completing teaching of probability theory, the proportion of mathematical statistics should strengthen. Because it contains a preliminary data analysis method, it can establish a theoretical foundation for students' future.

Secondly, exploratory exercises are added. As modern college graduates should have the ability of finding information, collecting information, organizing information and statistical inference. Consequently, in the selection of examples and exercises in addition to adding practical examples, especially from the practical problems in the original materials and data examples, students should complete extracurricular investigation report, describe investigation process and analysis survey results according to the teaching content. This work can increase students' learning interest and realize mathematical charm. Moreover, the foundation is established for future research and thesis writing.

Thirdly, let the students participate the teaching reform. Students can investigate using the theory of probability theory and mathematical statistics and participate in feasibility study of teaching material and teaching method reform together with teachers. Moreover, they can take as bystanders to adopt teaching measure theory to assist in formulation of evaluation scheme and implementation of the assessment work, so as to achieve the practical purpose.

\section{Highlighting the ERA OF Teaching}

At present, we are in an information age, knowledge updates faster and faster, the ability of collecting information, processing information and applying information is an indispensable index to examine modern talents. However, the content of probability theory and mathematical statistics is lack of time character and progressiveness, the modern achievements of probability theory and mathematical statistics are not reflected, so as not to adapt to social development and scientific progress.

From 1995, cluster analysis, factor analysis and other multivariate statistical content were added to the textbook of the national statistical teacher qualification examination. For instance, the research achievements of multivariate statistical appeared in many academic journals, such as industry, agriculture, medicine, biology, finance, insurance, education teaching research and so on. Moreover, the statistical software package was mostly used in data analysis. Thus, the applications of statistical methods are rapidly extended to all walks of life. Therefore, the content of multivariate statistics can be added to the textbook, such as factor analysis, cluster analysis, discriminate analysis and so on. If teachers consider that teaching time and difficulty can not be too high, it can be reduced, and then main method can be introduced by the practical example, or the multivariate statistics can be as an elective course, when the statistical methods are introduced, the related statistical software packages are added. In the process of teaching, if conditions allow, experiment on machine of statistical software can be arranged to help students understand and use statistical software.

\section{INTERACTIVE HeURISTIC TEACHING}

The teaching process is the interaction between teachers and students; teachers must be based on students in the teaching process, the teaching method should help students to master knowledge. Teachers can not only put forward enlightening problems to discuss between teachers and students in the teaching process, but also correct the error of students' exercises. Of course, teachers can counsel students to understand them by the web, mail, chat and other method. Here, classroom teaching as an example carry out Interactive heuristic teaching.

For example, when the laws of large numbers are taught, the following question can present.

Firstly, we would like to know how much life of a manufacturer's electronic products is. The used method is generally through simple random sampling method for a certain number of samples.

Secondly, in order to test the life of these electronic samples, the average value of the lifetime is calculated. We find that the average life expectancy is more stable by increasing the number of samples. We can also use the software by way of pictures to show change in average, let the students guess what happens behind.

Thirdly, we should know what value can be taken as the life of the electronic product, compared with definition method of probability, what are the similarities between them? At the same time, compared with the limit definition in advanced mathematical, what are the differences between them? How to describe this phenomenon through strict probability theory and mathematical statistics language? And so on.

In summary, for probability theory and mathematical statistics, interactive heuristic teaching can arouse students' subjective and learning enthusiasm by putting heuristic questions, discussing with each other and coaching students. Accordingly, the ability of students' analysis and solve problem can be cultured by this method.

\section{CONCLUSION}

Probability theory and mathematical statistics is studied as an important subject of random phenomena, and it plays an important role in solving many practical problems. From authors' teaching practice, this paper puts forward some 
suggestions in the teaching process, so as to improve the quality of teaching, enhance students' ability to analyze and solve problem for probability theory and mathematical statistics.

\section{ACKNOWLEDGMENT}

This work is supported by the Teaching Research Project of Xi'an University of Technology under Grant No. xjy1414.

\section{REFERENCES}

[1] W. Yang, Probability Theory and Mathematical Statistics. Beijing: Science Press, 2013, pp. 26-32. (In Chinese)

[2] X. Ma and W. Feng, "The practice and exploration of introductory teaching of probability theory and mathematical statistics," College Mathematics, vol. 29, pp. 139-141, April 2013. (In Chinese)
[3] H. Liu, "On the teaching exploration of probability theory and mathematical statistics," Journal of Anyang Normal College, vol. 26, pp. 132-135, May 2010. (In Chinese)

[4] X. Ding, "Developing students' thinking ability in the teaching of probability and statistics", Journal of Hengshui Normal College, vol. 5, pp. 73-75, April 2003. (In Chinese)

[5] S. He and $\mathrm{M}$. Li, "Grasping the characteristics of the classroomimproving the quality of classroom teaching”, Petroleum Education, vol. 105, pp. 82-83, February 2001.

[6] Z. Ni and M. Chen, "Modern teaching method of probability and statistics of technology focusing on statistics idea", College Mathematics, vol. 20, pp. 21-23, February 2004. (In Chinese)

[7] D. Zhang and S. Mao, "The cultivation of random mathematics thinking in the teaching of high school probability statistics", CurriculumTextbook-Teaching Methods, vol 9, pp. 39, August 2003.

[8] L. Yuan, "Discussion on teaching reform of normal probability and statistics", Journal of Shandong Normal University, vol. 19, pp. 87-89, April 2004. (In Chinese)

[9] S. Yan, "The reform of Chinese mathematics education for twenty-first century", Journal of Mathematics Education, vol 2, pp. 1-3, January 1996. (In Chinese) 